\title{
Is enrichment culture necessary for the isolation of Campylobacter jejuni from faeces?
}

\author{
DN HUTCHINSON, FJ BOLTON \\ From the Public Health Laboratory, Preston Infirmary, Meadow Street, Preston, Lancashire, PRI 6PS
}

SUMMARY The role of enrichment culture for the isolation of Campylobacter jejuni from faeces is discussed. It is concluded that enrichment culture is only necessary for those specimens where it is anticipated that the number of organisms is likely to be low. In a trial of a blood free enrichment broth (CCD broth) and the modified Preston enrichment broth the latter gave significantly superior results.

Six years ago Skirrow described the first selective agar for the direct isolation of Campylobacter jejuni from the faeces of persons with enteritis.' Thus microbiologists, worldwide, were stimulated to recognise this "new" pathogen. Subsequently several other selective media have been described ${ }^{2-4}$ which can be used for the isolation of the organisms from faeces and environmental specimens.

Enrichment techniques for the isolation of campylobacters from environmental specimens are almost routine and although the use of enrichment broth for the isolation of the organism from human faeces has been undertaken, it is not widely practised. Tanner and Bullin ${ }^{5}$ advocated the use of alkaline peptone water followed by subculture onto Skirrow's agar. ${ }^{1}$ Blaser et al, ${ }^{6}$ Bolton and Robertson, ${ }^{4}$ Bolton et al, ${ }^{7}$ Chan \& McKensie ${ }^{8}$ and Martin et $\mathrm{al}^{9}$ all found increased isolation rates following selective enrichment culture but Gilchrist et al ${ }^{10}$ were unable to demonstrate an advantage over direct plating.

During the trial of a blood-free selective medium (CCD agar) (unpublished data) it was decided to evaluate the medium as an enrichment broth (CCD broth) for faecal culture. A comparison with the modified Preston enrichment broth ${ }^{7}$ was made and the optimal subculture time determined.

This paper presents the findings of these studies and discusses those situations in which enrichment culture of faeces may be of value.

\section{Material and methods}

BLOOD FREE SELECTIVE MEDIUM (CCD AGAR)

The following ingredients are added to one litre of

Accepted for publication 11 August 1983 deionised water: Nutrient Broth No 2 (Oxoid) $25 \mathrm{~g}$, New Zealand agar (Davies) $12 \mathrm{~g}$, Bacteriological Charcoal (Oxoid) $4 \mathrm{~g}$, casein hydrolysates (Oxoid) $3 \mathrm{~g}$. Ten millilitres of $10 \%$ aqueous sodium deoxycholate $(\mathrm{BDH}), 5 \mathrm{ml}$ of $5 \%$ aqueous ferrous sulphate and $5 \mathrm{ml}$ of $5 \%$ aqueous sodium pyruvate are added to the basal medium to give final concentrations of $0.1 \%, 0.025 \%$ and $0.025 \%$ respectively. The medium should be adjusted to $\mathrm{pH} 7.4$ and sterilised by autoclaving at $121^{\circ} \mathrm{C}$ for $15 \mathrm{~min}$. Oneo millilitre of a $10000 \mathrm{mg} / \mathrm{l}$ aqueous solution of cephazolin (Eli Lilly and Co Ltd) should be added tog the cooled molten agar to give a final concentration of $10 \mathrm{mg} / \mathrm{l}$.

A selective enrichment broth was also prepared which had a similar formulation except for the omission of agar and the addition of sodium metabisulphite at a final concentration of $0.025 \%$. The broth medium (CCD broth) was distributed in $6 \mathrm{ml}$ volumes in screw capped $1 / 4 \mathrm{oz}(7 \mathrm{~g})$ bijoux containers.

\section{BLOOD CONTAINING SELECTIVE MEDIUM (PRESTON AGAR) ${ }^{4}$}

This was prepared to the following formulation: Nutrient Broth No 2 (Oxoid) $25 \mathrm{~g} / \mathrm{l}$, New Zealand Agar (Davies) $12 \mathrm{~g} / 1, \mathrm{pH} 7.4$ and sterilised by autoclaving at $121^{\circ} \mathrm{C}$ for $15 \mathrm{~min}$. Saponin-lysed horse blood $5 \%$, polymixin sulphate $5,000 \mathrm{IV} / \mathrm{l}$, trimethoprim lactate $10 \mathrm{mg} / \mathrm{l}$, rifampicin $10 \mathrm{mg} / \mathrm{l}$ and cyclohexamide $100 \mathrm{mg} / \mathrm{l}$ are added to the cooled molten agar prior to pouring.

The modified Preston enrichment broth contains similar constituents with the exception of agar and with the addition of ferrous sulphate, sodium metabisulphite and sodium pyruvate (FBP supplement) ${ }^{11}$ each at a final concentration of $0.025 \%$. The broth was distributed in $6 \mathrm{ml}$ volumes in screw capped $1 / 4 \mathrm{oz}(7 \mathrm{~g})$ bijoux containers. 
Table 1 Comparison of campylobacter isolation from direct plating and enrichment culture of faeces

\begin{tabular}{llll}
\hline $\begin{array}{l}\text { Direct plating } \\
\text { on CCD agar and }\end{array}$ & $\begin{array}{l}\text { Enrichment } \\
\text { Preston agar }\end{array}$ & $\begin{array}{l}\text { Enrichment } \\
\text { Preston broth }\end{array}$ & $\begin{array}{l}\text { Total No } \\
\text { of isolations }\end{array}$ \\
\hline+ & + & + & 34 \\
+ & - & + & 2 \\
- & + & + & 2 \\
- & - & + & 3 \\
\hline
\end{tabular}

\section{FAECAL SPECIMENS}

Two hundred and sixty-two faecal specimens, from patients with gastroenteritis, were cultured on the day of arrival in the laboratory. Each specimen was sampled with a cotton tipped swab. This faecal swab was inoculated directly onto both CCD agar and Preston agar and the inoculum was spread out to produce discrete colonies. The plates were incubated at $42^{\circ} \mathrm{C}$ in a microaerobic atmosphere obtained by evacuating anaerobic jars to $500 \mathrm{~mm} \mathrm{Hg}$ and refilling with $10 \% \mathrm{CO}_{2}$ in $\mathrm{H}_{2}$. Plates were examined after $24 \mathrm{~h}$ and $42 \mathrm{~h}$ incubation.

Enrichment culture was performed using faecal swabs to inoculate faeces directly into CCD broth and modified Preston enrichment broth. These were incubated at $42^{\circ} \mathrm{C}$ aerobically with the tops tightly closed and subcultured after $24 \mathrm{~h}$ and $42 \mathrm{~h}$ onto plates of CCD agar and Preston agar. Subculture plates were incubated microaerobically at $42^{\circ} \mathrm{C}$ for up to $42 \mathrm{~h}$.

Differences between test methods were analysed statistically using McNemar's test. ${ }^{12}$

\section{Results}

Forty-one isolations of Campylobacter jejuni/coli were made from 262 specimens following enrichment culture methods compared with 36 isolates obtained on direct plating (Table 1). All campylobacters isolated on direct culture were also isolated following enrichment culture.

The results (Figure) show that all of the 41 isolates were obtained after enrichment in the Preston broth and 36 were recovered from the CCD broth. The number of isolations made from the two
Isolation of campylobacters from enrichment cultures of 262 faecal specimens

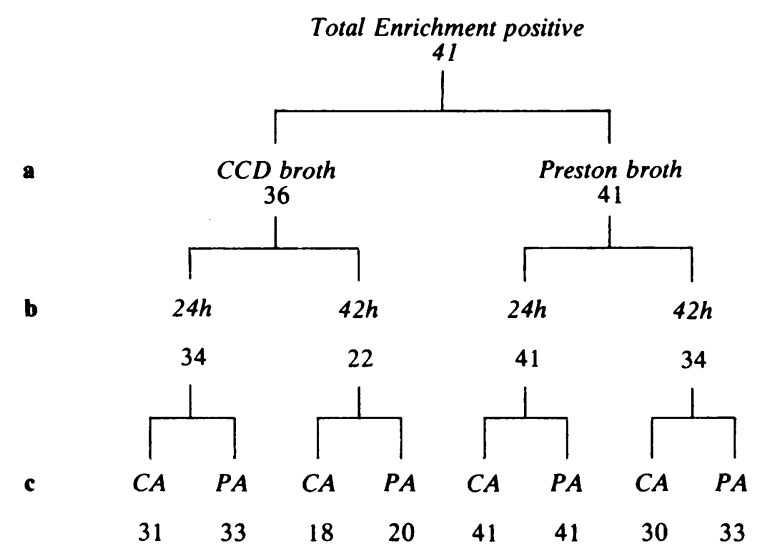

Key:

a Enrichment broths

b Time of subculture of enrichment broths

c Subculture medium: CA (CCD agar), PA (Preston agar)

enrichment broths following subculture at two different times is also shown in the Figure. Both the modified Preston broth and the CCD broth gave a significantly greater number of isolations if subcultured after $24 \mathrm{~h}$ instead of $42 \mathrm{~h}$.

In all but one sequence subculture onto Preston agar proved more satisfactory than subculture onto CCD agar but in no case was the difference statistically significant $(p<0.05)$. The effectiveness of the various combinations of broth and agars to reduce contamination is given in Table 2 . The growth of contaminants was significantly greater in CCD broth subcultured to $C C D$ agar than in the other three combinations $(p>0.001)$.

In this study the modified Preston enrichment broth was significantly $(0.05>p>0.01)$ superior to the CCD broth but under optimum conditions, ie $42^{\circ} \mathrm{C}$ incubation and subculture at $24 \mathrm{~h}$, it did not matter which of the two selective agars was used for subculture.

Table 2 No of selective broths which grew contaminating organisms following culture of 262 faeces samples

\begin{tabular}{lllllll}
\hline $\begin{array}{l}\text { Incubation } \\
\text { temperature }\end{array}$ & $\begin{array}{l}\text { Subculture } \\
\text { time }\end{array}$ & \multicolumn{2}{l}{$\begin{array}{l}\text { CCD broth } \\
\text { Subculture medium }\end{array}$} & & \multicolumn{2}{l}{$\begin{array}{l}\text { Preston broth } \\
\text { Subculture medium }\end{array}$} \\
\cline { 2 - 4 } & CCD agar & Preston agar & & CCD agar & Preston agar \\
\hline $42^{\circ} \mathrm{C}$ & $24 \mathrm{~h}$ & $118(45)$ & $11(4)$ & $21(8)$ & $8(3)$ & $12(5)$ \\
\hline
\end{tabular}

Figures in parentheses are percentages. 


\section{Discussion}

It has been recognised for many years that enrichment culture of faeces is necessary for the optimum detection of Salmonella infection whereas in acute Shigella infections the organisms are readily isolated on direct culture. The role of enrichment culture for the routine isolation of campylobacters from faeces has not been clearly defined. The possible value of enrichment is demonstrated in this study by the $14 \%$ increase in the number of isolations following enrichment culture.

Of the five specimens positive only after enrichment culture three were convalescent specimens from known positive patients, and one was an "acute" specimen received in the laboratory five days after collection. The other specimen was from a patient whose illness had started when he was abroad and who still had minor symptoms present on his return. It is probable that in all of these specimens the number of viable campylobacter organisms was small and that enrichment allowed them to grow to a detectable level. Evidence to support this surmise was obtained during the initial trials of the Preston medium 4 when it was found that four known campylobacter positive specimens which were positive only after enrichment and subculture contained $<10^{4}$ organisms per gram of faeces. It is most likely that a reduction in the number of campylobacters and overgrowth of contaminants accounted for the findings of Martin et al. ${ }^{9}$ These workers were able to reisolate campylobacters from only 13/19 direct culture positive human faecal specimens which had been stored at $4^{\circ} \mathrm{C}$ for 3-4 w. However using brucella broth as the base for a selective enrichment medium they were able to reisolate campylobacters from all 19 specimens. Also using the enrichment broth three additional isolations were made from amongst the batch of direct culture negative faeces similarly stored; a $16 \%$ increase in isolation rate.

The value of comparisons between direct plating and enrichment techniques depends upon the selective agar used for direct plating, the type of enrichment medium the subculture medium and other variables including, temperature of incubation, time of reading plates and time of subculture of the enrichment medium. Gilchrist et al ${ }^{10}$ concluded that for the isolation of campylobacters from faeces, enrichment in a selective thioglycollate broth was only equivalent to direct plating onto selective agars and in their experience made diagnosis slower. However Blaser et $a l^{6}$ using a similar medium found a significant increase in the isolation rate following enrichment whilst Chan and Mackenzie ${ }^{8}$ using a semi-solid enrichment medium achieved a $6 \%$ increase in isola- tion over direct culture on a modified Skirrow medium. Riberio et al $^{13}$ using Skirrow's agar for both direct inoculation and subculture reported a 74\% increase in the number of isolations from faeces following the use of the Preston enrichment broth. This contrasts with our results when using the Preston agar for direct and subculture plating. Using the Preston enrichment broth we found a $15 \%$ increase in isolation of campylobacters from human faeces. ${ }^{7}$

Although there is an increasing amount of evidence supporting the value of enrichment culture for the isolation of campylobacters we do not think it should be used routinely. It is our opinion that for the isolation of Campylobacter jejuni/coli direct culture onto a good selective agar is adequate for the examination of human faeces collected from subjects with acute diarrhoea. However, enrichment cultures for campylobacter isolation should be considered for those faecal specimens where there has been delay in the transit of the specimen to the laboratory or where the only specimen collected is one taken in the convalescent phase of a diarrhoeal illness.

\section{References}

'Skirrow, MB. Campylobacter enteritis: a "new" disease. Br Med J. 1977;ii:9-11.

${ }^{2}$ Lauwers S, De Boeck M, Butzler JP. Campylobacter enteritis i⿺廴 Brussels. Lancet 1978;i:604-5.

${ }^{3}$ Blaser M, Cravens J, Powers BW, Wang WL. Campylobacter enteritis associated with canine infection. Lancet 1978:ii:979-81.

${ }^{4}$ Bolton FJ, Robertson L. A selective medium for isolating Campylobacter jejuni/coli. J Clin Pathol 1982;35:462-7.

5 Tanner EI, Bullin CH. Campylobacter enteritis. $\mathrm{Br} \mathrm{Med} J$ 1977 ;ii:579.

- Blaser MJ, Berkowitz ID, Laforce M, Cravens J, Reller LB, Wang WL. Campylobacter enteritis, clinical and epidemiological features. Ann Intern Med 1979;91:179-85.

${ }^{7}$ Bolton FJ, Coates D, Hinchliffe PM, Robertson L. Comparison of selective media for isolation of Campylobacter jejuni/coli. J Clin Pathol 1983;36:78-83.

${ }^{8}$ Chan FTH, Mackenzie AMR. Enrichment medium and control system for isolation of Campylobacter fetus subsp jejuni from stools. J Clin Microbiol 1982;15:12-15.

9 Martin WT, Patton CM, Morris GK, Potter ME, Puhr ND. Selective enrichment broth medium for isolation of Campylobacter jejuni. J Clin Microbiol 1983;17:853-5.

${ }^{10}$ Gilchrist MJR, Grewell CM, Washington JA. Evaluation of media for isolation of Campylobacter fetus subsp jejuni from faecal specimens. J Clin Microbiol 1981;14:393-5.

$"$ George HA, Hoffman PS, Smibert RM, Krieg NR. Improved media for growth and aerotolerance of Campylobacter fetus. $J$ Clin Microbiol 1978;8:36-41.

12 Swinscow TDV. In: Statistics at square one. London: British Medical Association, 1977:30-32.

13 Riberio CD, Gray SJ, Price TH. A new medium for isolating Campylobacter jejuni/coli. J Clin Pathol 1982;35:1036-7.

Requests for reprints to: Mr FJ Bolton, Public Health Laboratory, Preston Infirmary, Meadow Street, Preston, $\square$ Lancashire, PR1 6PS, England. 